Research Article

\title{
Flood Simulation in South Carolina Watersheds Using Different Precipitation Inputs
}

\author{
Peng Gao iD, Gregory J. Carbone, and Junyu Lu \\ Department of Geography, University of South Carolina, 709 Bull Street, Columbia, SC 29208, USA \\ Correspondence should be addressed to Peng Gao; gaop@mailbox.sc.edu
}

Received 7 April 2018; Accepted 29 May 2018; Published 5 July 2018

Academic Editor: Yoshihiro Tomikawa

Copyright ( $\odot 2018$ Peng Gao et al. This is an open access article distributed under the Creative Commons Attribution License, which permits unrestricted use, distribution, and reproduction in any medium, provided the original work is properly cited.

\begin{abstract}
Flooding induced by extreme rainfall events causes tremendous loss of life and property and infrastructure failure. Accurate representation of precipitation, which has high variation in space and time, is critical to hydrologic model simulations and flood analyses. In this study, we examined responses of differently sized United States Geological Survey (USGS) hydrologic units to heavy precipitation using three different data sets. The first consists of rainfall observed at individual meteorological gauges. The second uses the National Centers for Environmental Prediction (NCEP) Environmental Modeling Center (EMC) $4 \mathrm{~km}$ gridded radar-estimated precipitation (GRIB) Stage IV data. The third one derives from the method we developed that blends gauge data with the spatial coverage of the Parameter-elevation Relationships on Independent Slopes Model (PRISM) data. We examined how two watersheds in South Carolina respond to the three different representations of heavy rainfall, using the Hydrologic Engineering Center's Hydrologic Modeling System (HEC-HMS) developed by the U.S. Army Corps of Engineers. We found that the latter two precipitation inputs that consider spatial representation of rainfall yielded similar performance and improved simulated streamflow as compared to simulation using rainfall observed at individual meteorological gauges. The method we developed overcomes the spatial sparsity of rain gauges required for interpolation and extends availability of precipitation surfaces. Our study advances the understanding of advantages and limitations of different precipitation products for flood simulation.
\end{abstract}

\section{Introduction}

Flooding is one of the most frequently occurring and costly natural hazards in the world, causing death and injury, displacement of communities, and loss of private and public properties [1]. Hydrological models improve understanding of hydrological processes and flood forecasting in ways that could mitigate impacts [2-6]. However, the performance of hydrological models depends on the spatial and temporal accuracy of rainfall data $[7,8]$.

The most widely used source of rainfall data is observations at rain gauges, which provide direct measurement of precipitation intensity and duration at individual points. Rain gauge observations are considered as the most accurate precipitation data source and provide the basis for evaluating and calibrating other precipitation products such as those based on radar data $[9,10]$. Data availability at some rain gauges spans several decades, which makes them a valuable data source for the study of historic extreme precipitation and associated flooding [11-14]. Despite the advantages of reliability and longtime coverage, rain gauge observations have poor representation of areal precipitation, especially where the gauge network is sparse $[15,16]$. The network of rain gauges with high temporal resolution is particularly limited. In the United States, there are over 25,000 daily recording stations and only 8,000 hourly stations [17]. Rain gauge observations inadequately capture the spatial and temporal variability of short-duration storm events, especially in small catchments, thus limiting the accuracy of streamflow simulation [18].

In contrast to the shortcomings of rain gauge observations in representing spatial and temporal structures of precipitation, radar precipitation data provide a better capture of precipitation over spatial and temporal scales that are paramount to hydrologic applications [19]. Radars do not directly measure rainfall amounts but estimate the rainfall rate via an empirical relationship with the radar reflectivity factor. Great efforts have been exerted to improve 
estimations of the reflectivity factor, calibrate radar data, and increase their usability [20-23]. The evolvement of radar data in the United States has experienced four generations [24-27]. The most recent generation Stage IV radar data take advantage of manual quality control performed on the Stage III data and have mosaiced Stage III data covering the entire continental United States, providing hourly precipitation at the scale of $4 \mathrm{~km}$ polar stereographic grids starting from January 1, 2002 [27]. Nevertheless, the temporal coverage of radar data (i.e., 2002 to present) limits the usage of radar for the hydrological simulation prior to 2002 .

The potential and effectiveness of using radar data to improve hydrological simulations has captured the interest of the research and operational communities for some time. Comparisons of hydrological simulations using radar and gauge data as precipitation input have been conducted. Lopez et al. suggested that the Stage IV radar product had better hydrologic skills over other rainfall data sources based on their investigation in the Treja catchment in Italy using a rainfall-runoff model named "geomorphological instantaneous unit hydrograph (GIUH)" [28]. Similar findings were concluded from hydrologic simulation conducted in four river basins in the United States using the distributed Clark model [29]. One particular interest is tests on rainfall gauge data, radar data, and remote-sensed rainfall products (e.g., Tropical Rainfall Measuring Mission (TRMM)) using the Hydrologic Engineering Center's Hydrologic Modeling System (HEC-HMS) developed by the U.S. Army Corps of Engineers [30], which has been applied to a wide range of geographic areas for solving a variety of hydrological problems. Hamedi and Fuentes examined the effectiveness of Gridded Surface Subsurface Hydrologic Analysis (GSSHA) and HEC-HMS to predict outlet hydrographs in the Park City catchment basin in Utah using next-generation radar (NEXRAD) and gauge data as input and suggested the reliability of using NEXRAD [19]. Investigation over the Brays Bayou watershed in Houston proved simulated outflows from radar data to be accurate, and in some cases more accurate, than those from rain gauges [31]. However, the study in two subbasins of the Cumberland River basin in Middle Tennessee found that radar-driven simulations offered no improvement in predicting the streamflow volume, magnitude, and time to peak over gauge-driven simulations [15].

The comparison of hydrologic simulations using radar and gauge precipitation data involves the spatial and temporal resolution and coverage of the rainfall data, model mechanisms (e.g., simplicity or complexity and parameterization), and watershed characteristics (e.g., size and climatologic and physiographic settings) [15, 32]. South Carolina was impacted by the heavy rainfall and flooding in October 2015 and Hurricane Matthew in October 2016. The former led to $\$ 138$ million paid losses and the failure of 52 dams $[33,34]$. The latter costs $\$ 116.9$ million federal disaster assistance for the survivors in South Carolina [35]. We assess the suitability of different precipitation data sources that are constrained by spatial and temporal coverage and resolutions of these data in the flood simulation using HEC-HMS for South Carolina. We also propose a new method that integrates merits of precipitation gauge data and the widely used gridded daily Parameter-elevation Relationships on Independent Slopes Model (PRISM) [36] data to overcome the sparsity of rain gauge data and test the effectiveness of the new method.

\section{Methods}

Flood simulation was conducted in the Gills Creek (hydrologic unit code (HUC): 0305011002; $193 \mathrm{~km}^{2}$ ) watershed in central South Carolina and Waccamaw (HUC: 03040206; $4277 \mathrm{~km}^{2}$ ) watershed at the border of South Carolina and North Carolina (Figures 1 and 2) using HEC-HMS [30]. One time period was selected to calibrate the model, and two other time periods were chosen to test the effects of different precipitation sources on model performance. Observed streamflow at United States Geological Survey (USGS) gauges within the investigated watersheds was ranked to obtain the percentiles of streamflow. Time periods with high streamflow that exceeded the 99 percentile were selected for calibration and testing, subject to the availability of streamflow and precipitation data (Tables 1 and 2). HECHMS was calibrated using a variety of data sources and methods. Topography was derived from the USGS National Elevation Dataset (NED), which provides gridded elevation values at $10 \mathrm{~m}$ spatial resolution. Soil data were obtained through the State Soil Geographic Database (STATSGO) maintained by the National Resource Conservation Service. Land use and land cover information was obtained from the National Land Cover Dataset 2011 created by USGS. The gridded curve number $(\mathrm{CN})$ technique suggested by the Soil Conservation Service (SCS), which enables spatially distributed infiltration calculations, was used to simulate infiltration loss. The $\mathrm{CN}$ technique quantifies the infiltration capacity area based on land use, soil and land cover type, and hydrologic soil group [37]. Translation of excess precipitation to runoff was conducted using the Clark unit hydrograph transformation [38]. Baseflow was modeled using an exponential decrease function.

We investigated the effects of three precipitation sources on flood simulation including (1) station observations (hereafter ST), (2) radar data (hereafter RD), and (3) station observations adjusted by the PRISM data which provide daily total precipitation in the continental United States, from 1981 to present (hereafter ST-PRISM) [36]. Station observations in the Automated Surface Observing System (ASOS) obtained from the Iowa Environmental Mesonet [39] are point-based precipitation values, while radar data [27] are areal representation of precipitation. Radar data were not developed fully until 2002, which constrains the data availability of areal representation of precipitation for flood simulation prior to 2002. Although the PRISM data provide areal representation of precipitation for a longer time period than radar data (i.e., 1981 to present), the daily temporal resolution of the PRISM data is not adequate for HEC-HMS which requires hourly precipitation inputs. To overcome this problem, we exploit the high temporal resolution of station observations and adjust these point-based precipitation values using gridded PRISM data with the following procedures: first, we selected candidate stations 


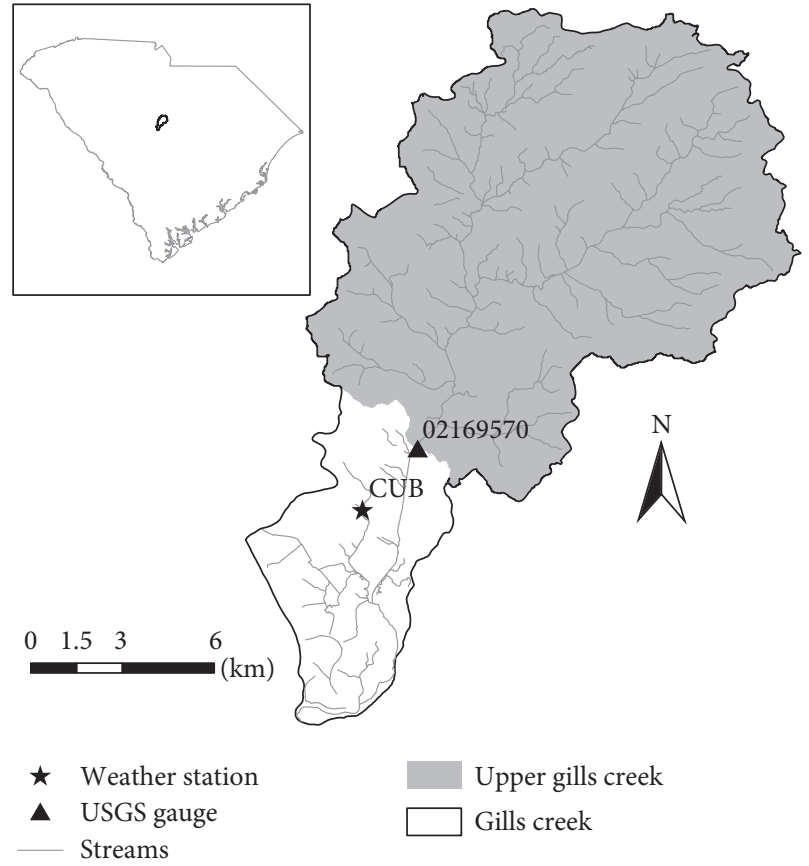

FIGURE 1: Gills Creek watershed and associated stations for flood simulation.

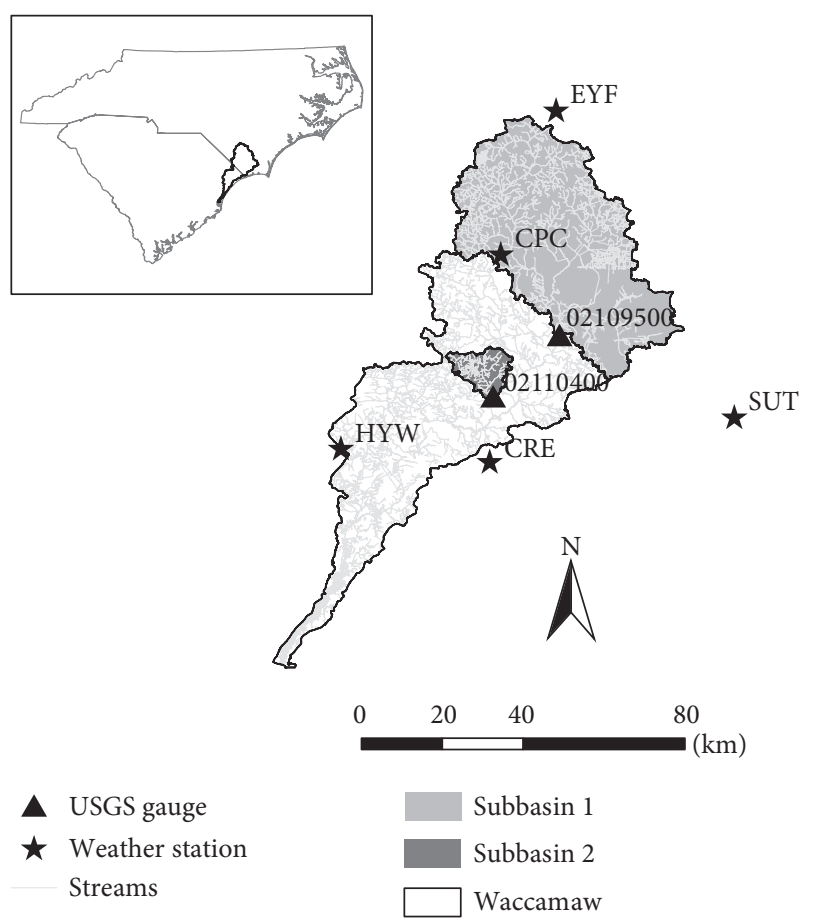

FIgURE 2: Waccamaw watershed and associated stations for flood simulation.

that are within or surrounding the watershed where flood simulation was conducted. Second, for each day, we identified the station whose daily total precipitation was closest to the areal daily total of PRISM on that day. Third, the hourly precipitation of the identified station was multiplied by the ratio between the areal daily total of PRISM and daily total of the station. In this way, the daily total precipitation of the station matched the areal daily total of PRISM. The approach takes the advantage of areal representation of PRISM data and high temporal resolution of station data (i.e., hourly observations).

Flood simulation on Gills Creek was compared against observed discharge at the USGS station of Gills Creek at Columbia SC (site ID: 02169570) to validate the simulated discharge of Upper Gills Creek subbasin (Figure 1). Precipitation data included station (ST) data from the observation at Columbia Owens Downtown Airport (CUB), radar (RD) data from the National Centers for Environmental Prediction (NCEP) Environmental Modeling Center (EMC) $4 \mathrm{~km}$ gridded radar-estimated precipitation (GRIB) Stage IV data [27], and hybrid (ST-PRISM) data from CUB and PRISM.

Flood simulation for the Waccamaw watershed was conducted in two individual subbasins. Streamflows observed at the USGS station of Waccamaw River at Freeland (site ID: 02109500) and Buck Creek near Longs, SC (site ID: 02110400), were used to validate the simulated streamflow of subbasins 1 and 2, respectively (Figure 2). Observations at Buck Creek near Longs, SC (site ID: 02110400), were not available for the second testing period (i.e., Sep 14-25, 1999). The precipitation data source varied for different subbasins and periods. In the second testing period, radar precipitation data were not available, and North Myrtle Beach (CRE) had the only available precipitation gauge. Precipitation data sources for subbasins 1 and 2 were different in the calibration and the first testing periods (Figure 2 and Table 3 ). The selection of precipitation stations was based on the closeness of stations to subbasins (Figure 2).

HEC-HMS was calibrated separately using point-based representation (i.e., ST) and two areal representations of precipitation (i.e., RD and ST-PRISM), which yielded a set of parameters for each of the three precipitation inputs. In the testing periods, flood simulation was conducted using the three calibrated models with the same precipitation inputs used to calibrate the models. Model performance was assessed using four statistical indices that compare the simulated streamflow against the observed streamflow: Nash-Sutcliffe Efficiency (NSE), $R$ square $\left(R^{2}\right), p$-bias, and root mean square error (RMSE) (see $[40,41]$ for descriptions). We also compared the total precipitation amount received in a watershed or subbasin and temporal patterns of precipitation during calibration and testing periods from three different data sources to investigate the effects of different precipitation inputs on flood simulation.

\section{Results}

The total precipitation amount derived from the two areal representations (i.e., RD and ST-PRISM) was close to each other in both watersheds and for different periods of calibration and testing (Figures 3 and 4). The largest difference was $17 \mathrm{~mm}$ over 9 days from October 2 to 10, 2015, in subbasin 2 of Waccamaw (Figure 4(d)). In contrast, the difference between the area-based and the point-based 
TABLE 1: Calibration and testing time periods and associated flow statistics of the Gills Creek watershed.

\begin{tabular}{lcccc}
\hline & Time period & Highest daily flow $\left(\mathrm{ft}^{3} \cdot \mathrm{s}^{-1}\right)$ & Date & $1 / 11 / 2014$ \\
\hline Calibration & $01 / 09 / 201422: 00$ to $01 / 11 / 201412: 00$ & 656 & $12 / 24 / 2014$ & Exceedance $(\%)$ \\
Testing 1 & $12 / 23 / 201411: 00$ to $12 / 25 / 201423: 00$ & 652 & 99.65 \\
Testing 2 & $09 / 22 / 201107: 00$ to $09 / 24 / 201106: 00$ & 661 & $9 / 23 / 2011$ & 99.64 \\
\hline
\end{tabular}

TABLE 2: Calibration and testing time periods and associated flow statistics of two subbasins in the Waccamaw watershed.

\begin{tabular}{llccccc}
\hline & & \multicolumn{1}{c}{ Time period } & Highest daily flow $\left(\mathrm{ft}^{3} \cdot \mathrm{s}^{-1}\right)$ & Date & Exceedance $(\%)$ \\
\hline \multirow{3}{*}{ Subbasin 1 } & Calibration & $02 / 03 / 2016$ 00:00 to 02/15/2016 23:00 & 7350 & $2 / 10 / 2016$ & 99.78 \\
& Testing 1 & $10 / 02 / 201512: 00$ to $10 / 11 / 201523: 00$ & 10900 & $10 / 8 / 2015$ & 99.94 \\
& Testing 2 & $09 / 14 / 199900: 00$ to 09/25/1999 23:00 & 30600 & $9 / 21 / 1999$ & 100.00 \\
\hline \multirow{2}{*}{ Subbasin 2 } & Calibration & $02 / 03 / 201600: 00$ to 02/15/2016 23:00 & 1390 & $2 / 5 / 2016$ & 99.83 \\
& Testing 1 & $10 / 02 / 201512: 00$ to 10/11/2015 23:00 & 2750 & $10 / 5 / 2015$ & 100.00 \\
\hline
\end{tabular}

Table 3: Precipitation data source used for the flood simulation in the Waccamaw watershed.

\begin{tabular}{|c|c|c|c|c|c|}
\hline \multirow{2}{*}{ Time periods } & \multirow{2}{*}{ Subbasin } & \multirow{2}{*}{ ST } & \multirow{2}{*}{$\mathrm{RD}$} & \multicolumn{2}{|c|}{ ST-PRISM } \\
\hline & & & & Candidate station(s) & Areal daily total \\
\hline \multirow{2}{*}{ Calibration (Feb 03-15, 2016) } & 1 & $\mathrm{CPC}$ & \multirow{2}{*}{ GRIB } & CPC, SUT, and EYF & \multirow{2}{*}{ PRISM } \\
\hline & 2 & CRE & & CPC, CRE, and HYW & \\
\hline \multirow{2}{*}{ Testing 1 (Oct $2-11,2015)$} & 1 & CPC & \multirow{2}{*}{ GRIB } & CPC, SUT, and EYF & \multirow{2}{*}{ PRISM } \\
\hline & 2 & CRE & & CPC, CRE, and HYW & \\
\hline \multirow{2}{*}{ Testing 2 (Sep 14-25, 1999) } & 1 & CRE & \multirow{2}{*}{ Not available } & CRE & \multirow{2}{*}{ PRISM } \\
\hline & 2 & CRE & & CRE & \\
\hline
\end{tabular}

CPC: Columbus County Municipal Airport; CRE: North Myrtle Beach; EYF: Elizabeth Town/Curtis Brown Field; HYW: Conway; SUT: Southport/Brunswick; GRIB: the National Centers for Environmental Prediction (NCEP) Environmental Modeling Center (EMC) $4 \mathrm{~km}$ gridded radar-estimated precipitation; PRISM: Parameter-elevation Relationships on Independent Slopes Model precipitation data.

representations of precipitation was much larger. The largest difference was $67 \mathrm{~mm}$ (ST-PRISM: $153 \mathrm{~mm}$ versus ST: $86 \mathrm{~mm}$ ) in subbasin 1 of Waccamaw from February 3 to 15 , 2016 (Figure 4(a)). The peaking time of the point-based representation and the two areal representations of precipitation was similar in most of the situations, except for a few unmatched peaks in the two subbasins of Waccamaw in October 2015 (Figures 4(c) and 4(d)).

Good calibrations were achieved using the three types of precipitation inputs (Figures 3(a), 4(a), and 4(b), and Tables 4 and 5). As for the performance in testing periods, the three precipitation inputs had good performance in subbasin 1 of Waccamaw in October 2015 (Figure 4(c) and Table 5). Overestimation was observed in Gills Creek in December 2014 and in subbasin 2 of Waccamaw in October 2015 for all the three precipitation inputs (Figures 3(b) and 4(d), and Tables 4 and 5). The ST-calibrated model suffered from severe overestimation, while the two areal representations of precipitation had some underestimation in Gills Creek in September 2011 (Figure 3(c) and Table 4). The ST-calibrated model had less underestimation than the model calibrated by the areal representation of precipitation (i.e., ST-PRISM) in subbasin 1 of Waccamaw in September 1999 (Figure 4(e) and Table 3).

\section{Discussion and Conclusion}

Precipitation amounts affected two aspects of model performance: parameterization during model calibration and the total amount of water that entered a watershed for flood simulation. In Gills Creek, because of the similar amount and temporal patterns of the area-based and the point-based representations of precipitation in the calibration period, calibration using the three precipitation inputs yielded similar parameters and model performance (Figure 3(a)). However, during testing periods, precipitation estimates differed; thus, total precipitation became the most influential factor on model performance. The overestimation by the STcalibrated model occurred because during testing periods, ST-estimated precipitation was much higher than RDestimated or ST-PRISM-estimated precipitation (Figures 3(b) and $3(\mathrm{c})$ ). Overall, models calibrated by the two areal representations of precipitation achieved better performance than the ST-calibrated model in Gills Creek.

In Waccamaw, because of much lower station precipitation (ST) compared to the two areal estimates in the calibration period (Figures 4(a) and 4(b)), the potential retention scale factors in subbasins 1 and 2 were set to very low values. This reduced the loss of precipitation and allowed a similar calibration to the RD-calibrated and STPRISM-calibrated models for comparisons in testing periods. In subbasin 2, the low value of the potential retention scale factor and the two much larger peaks of ST caused overestimation for the ST-calibrated model (Figure 4(d) and Table 5). In subbasin 1, the potential retention scale factor was particularly set to an extremely low value, although this setting yielded good simulations in the two 


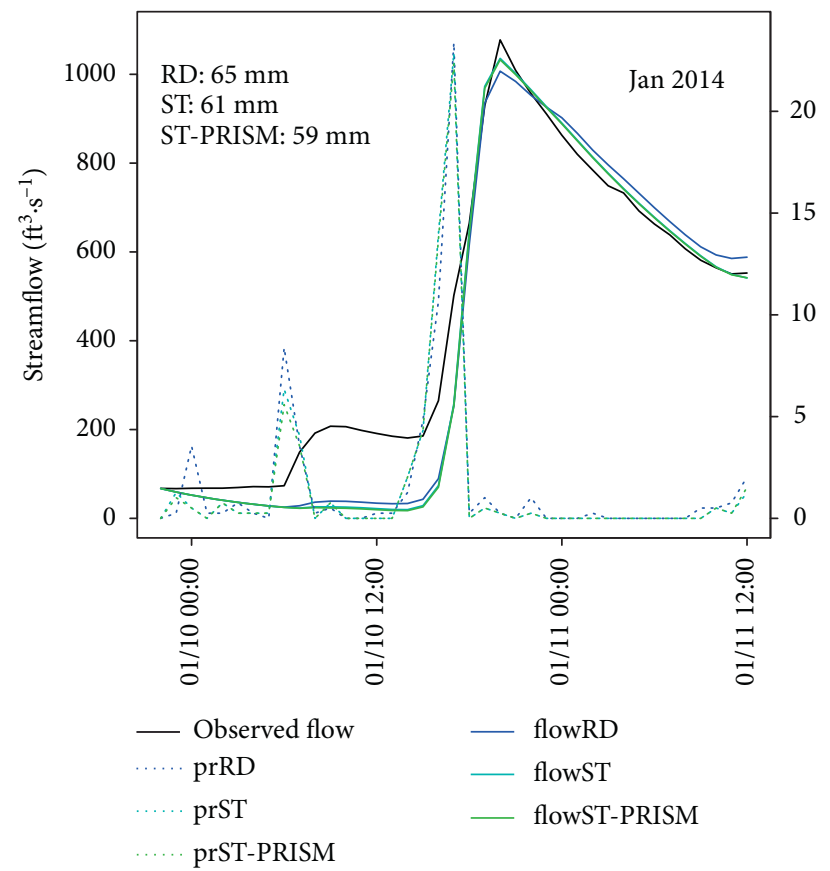

(a)

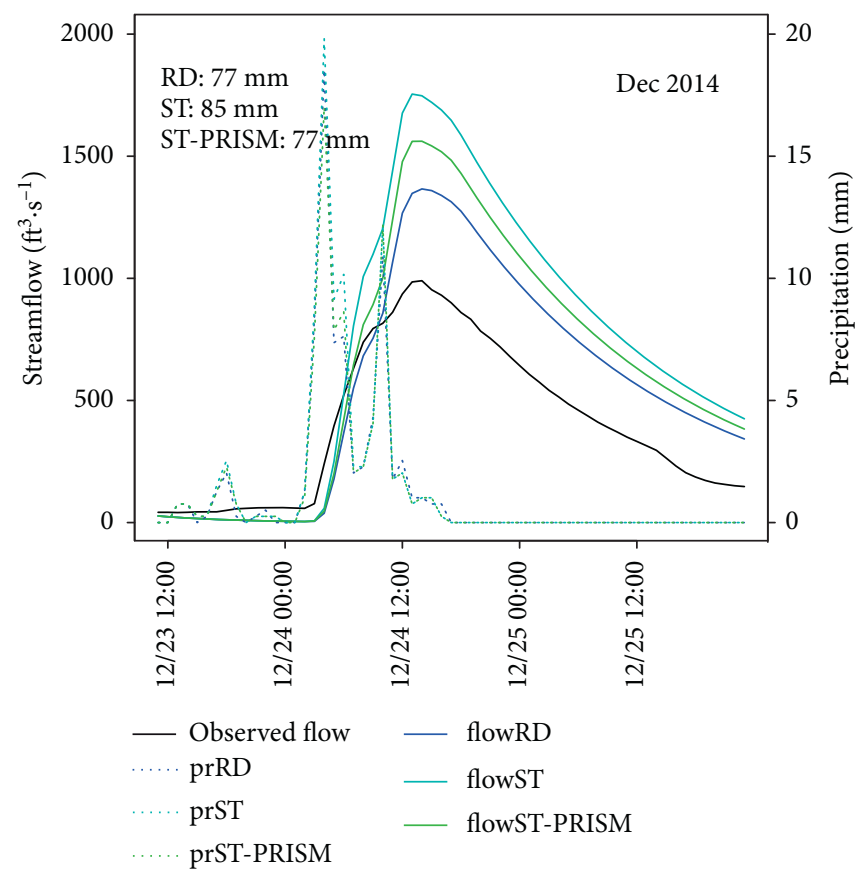

(b)

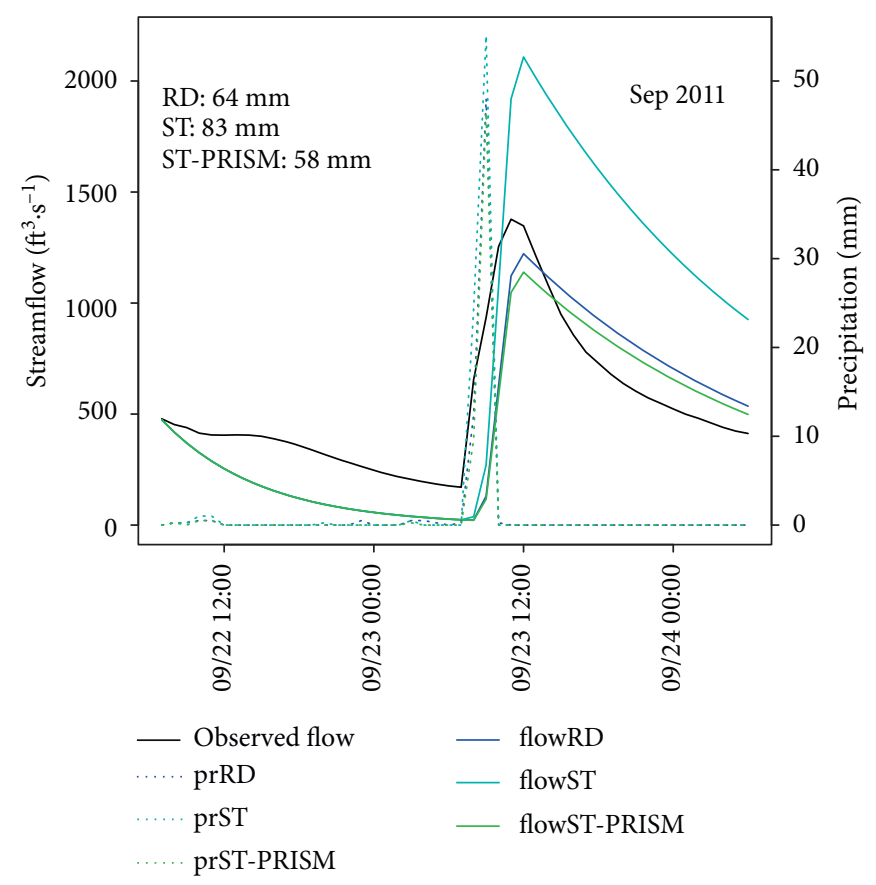

(c)

Figure 3: Observed and simulated streamflows (solid lines) in Gills Creek using three precipitation inputs (dash lines) for calibration (a) and two testing periods (b, c). ST: station observations, RD: radar data, and ST-PRISM: station observations adjusted by the gridded daily Parameter-elevation Relationships on Independent Slopes Model (PRISM) precipitation data.

testing periods for the ST-calibrated model (Figures 4(c) and $4(\mathrm{e}))$. Others have noted model parameterization differences between calibrations with the radar and gauge precipitation [42]. They underscored the importance of linking calibration parameters to realistic processes. The potential retention scale factor in the ST-calibrated model was set to very low values, which indicated the watershed had little ability to retain precipitation. However, land use and land cover data from the National Land Cover Dataset suggested $57.8 \%$ of the watershed is covered by either forest or wetlands which can retain considerable precipitation amounts. Therefore, although the ST-calibrated model achieved good performance in the two testing periods in subbasin 1, parameterization of the ST-calibrated model 


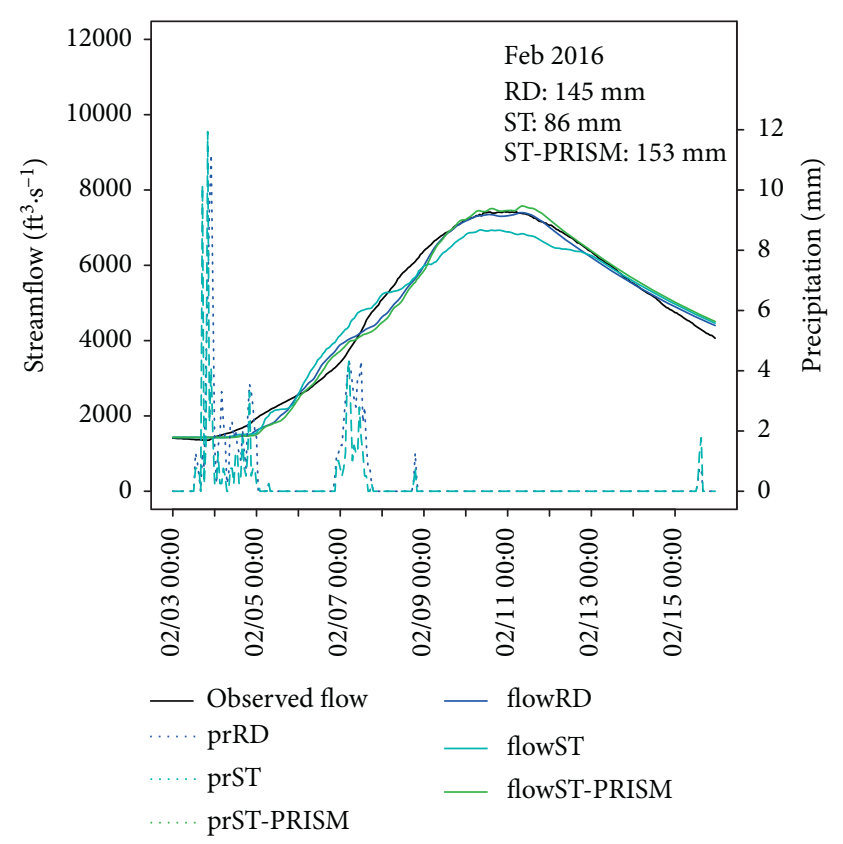

(a)

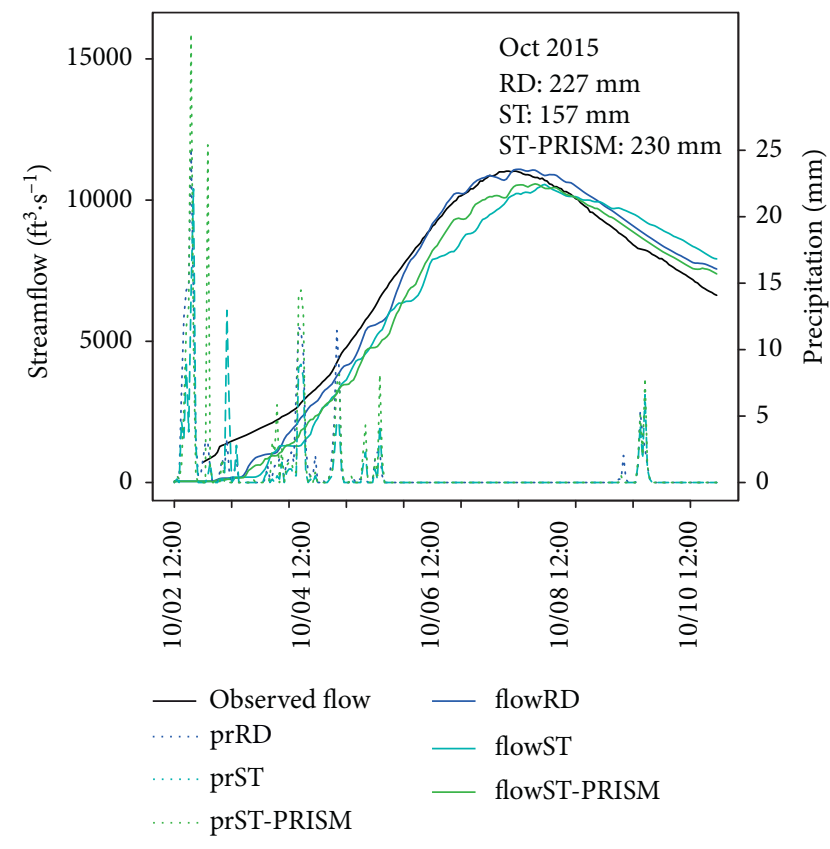

(c)

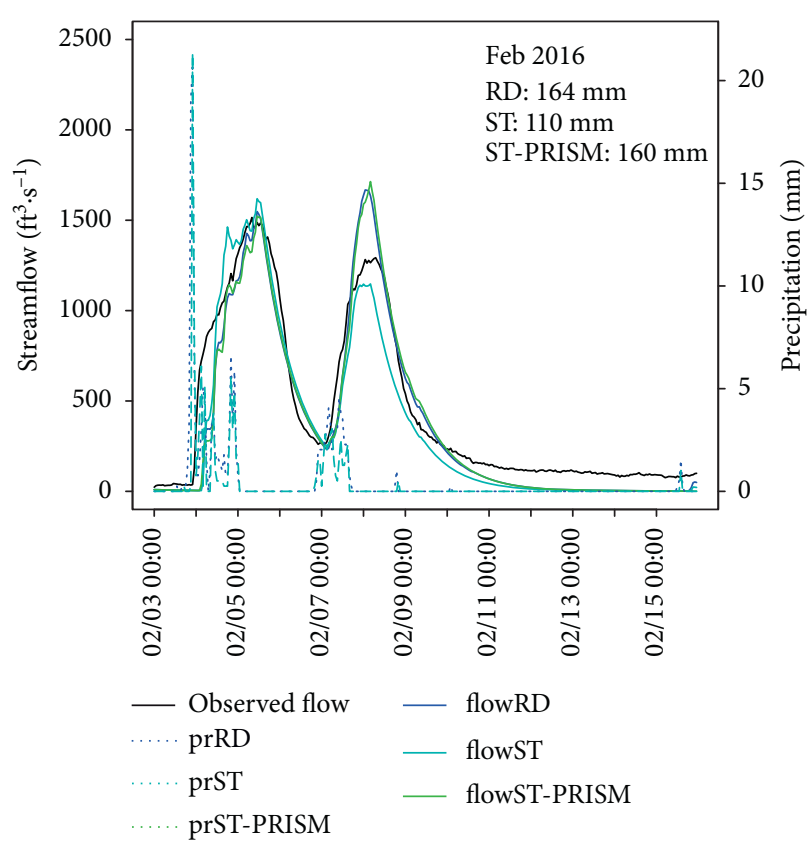

(b)

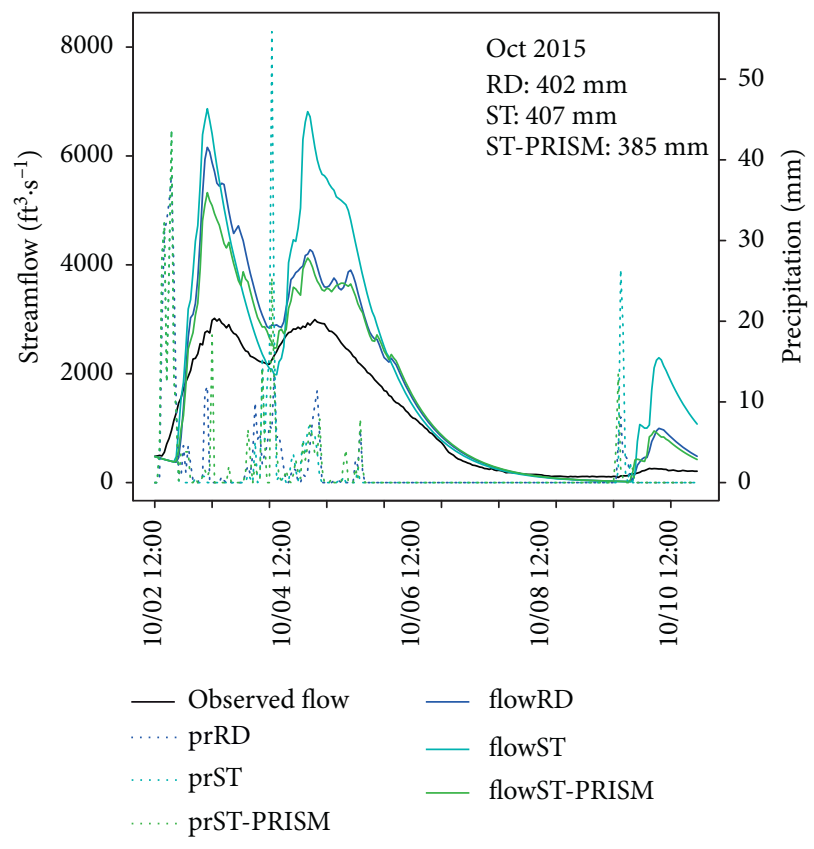

(d)

Figure 4: Continued. 


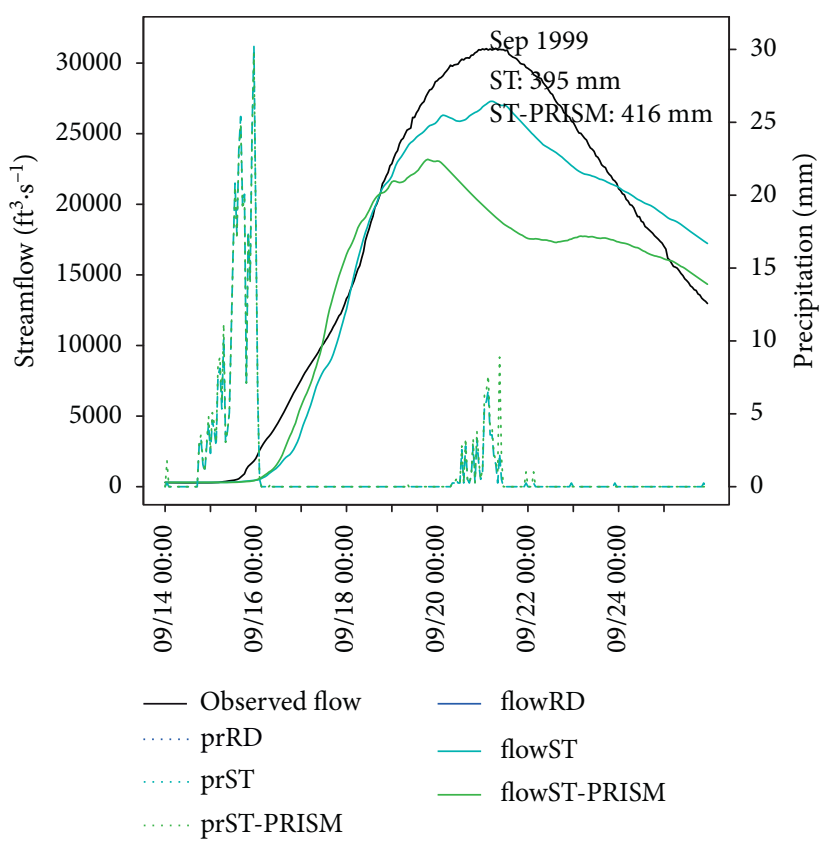

(e)

FiguRe 4: Observed and simulated streamflows (solid lines) in two subbasins of Waccamaw (a, c, and e for subbasin 1 and $b$ and $d$ for subbasin 2) using three precipitation inputs (dash lines) for calibration (a, b) and testing period(s) (c-e). ST: station observations, RD: radar data, and ST-PRISM: station observations adjusted by the gridded daily Parameter-elevation Relationships on Independent Slopes Model (PRISM) precipitation data.

TABLe 4: Model performance in the Gills Creek watershed.

\begin{tabular}{lccccc}
\hline & Precipitation input & NSE & $p$-bias & RMSE & $R^{2}$ \\
\hline & RD & 0.920 & 9.648 & 93.209 & 0.963 \\
Calibration $(01 / 09 / 201422: 00$ to $01 / 11 / 201412: 00)$ & ST & 0.915 & 11.301 & 96.014 & 0.966 \\
& ST-PRISM & 0.912 & 11.667 & 97.302 & 0.965 \\
\hline \multirow{3}{*}{ Testing 1 (12/23/2014 11:00 to 12/25/2014 23:00) } & RD & 0.419 & -38.546 & 240.828 & 0.899 \\
& ST & -0.774 & -76.344 & 420.921 & 0.929 \\
\hline & ST-PRISM & -0.073 & -56.654 & 327.351 & 0.910 \\
Testing $2(09 / 22 / 201107: 00$ to $09 / 24 / 201106: 00)$ & RD & 0.392 & 15.250 & 242.225 & 0.643 \\
& ST & -1.756 & -35.377 & 515.546 & 0.642 \\
& ST-PRISM & 0.409 & 20.081 & 238.641 & 0.641 \\
\hline
\end{tabular}

TABle 5: Model performance in the Waccamaw watershed.

\begin{tabular}{|c|c|c|c|c|c|c|c|c|c|}
\hline & \multirow{2}{*}{$\begin{array}{l}\text { Precipitation } \\
\text { input }\end{array}$} & \multicolumn{4}{|c|}{ Subbasin 1} & \multicolumn{4}{|c|}{ Subbasin 2} \\
\hline & & NSE & p-bias & RMSE & $R^{2}$ & NSE & $p$-bias & RMSE & $R^{2}$ \\
\hline \multirow{3}{*}{ Calibration $(02 / 03 / 201600: 00$ to $02 / 15 / 201623: 00)$} & $\mathrm{RD}$ & 0.987 & 1.257 & 233.398 & 0.988 & 0.888 & 13.403 & 154.152 & 0.918 \\
\hline & ST & 0.970 & 1.568 & 361.065 & 0.975 & 0.882 & 20.411 & 158.550 & 0.924 \\
\hline & ST-PRISM & 0.982 & 0.575 & 277.139 & 0.983 & 0.881 & 13.136 & 159.281 & 0.910 \\
\hline \multirow{3}{*}{ Testing $1(10 / 02 / 201512: 00$ to $10 / 11 / 2015$ 23:00) } & $\mathrm{RD}$ & 0.962 & 1.638 & 637.288 & 0.987 & 0.252 & -45.261 & 935.987 & 0.918 \\
\hline & ST & 0.877 & 8.003 & 1145.282 & 0.931 & -0.653 & -67.806 & 1391.661 & 0.830 \\
\hline & ST-PRISM & 0.924 & 8.290 & 902.166 & 0.972 & 0.559 & -36.076 & 719.125 & 0.937 \\
\hline \multirow{2}{*}{ Testing $2(09 / 14 / 199900: 00$ to $09 / 25 / 1999$ 23:00) } & ST & 0.939 & 7.613 & 2635.977 & 0.956 & & & & \\
\hline & ST-PRISM & 0.711 & 20.925 & 5763.335 & 0.858 & & & & \\
\hline
\end{tabular}

did not reflect realistic hydrological processes. Overall, models calibrated by the two areal representations of precipitation (RD and ST-PRISM) had similar performance-better than the ST-calibrated model (Figure 4 and Table 5).
Our study underscores the importance of spatial representation of precipitation for flood simulation $[7,18,43,44]$ as observations at a single station (ST) did not reliably represent the precipitation surface. Yet, despite 
many new spatial precipitation products (e.g., radar and satellite estimates), resulting flood simulations show inconsistent performance. Our findings are similar to those of the studies $[29,45,46]$, which suggest precipitation input using radar data produced better hydrological simulation than station observations, but different from those of the study [15] which found no improvement in hydrological simulation using radar data. Several factors could contribute to these disparities, including local errors in radar and rain gauge data, modeling simplicity or complexity, varying watershed sizes, choice of runoff generation mechanisms, or accuracy of watershed parameters and calibration [32].

In terms of the quality of station observations, radar data, and the PRISM data, rain gauge observations are considered as the most accurate precipitation data source. They are often used to evaluate the accuracy of radar data $[9,10]$. The PRISM data are the official spatial climate data sets of the U.S. Department of Agriculture and have been produced using methods that consider location, elevation, coastal proximity, topographic facet orientation, vertical atmospheric layer, topographic position, and orographic effectiveness of the terrain and incorporate radar observations. Readers are referred to the study [36] for the uncertainty assessment of PRISM data.

Also unsolved is the optimal method for incorporating gauge data to create a spatial representation of the precipitation surface for flood simulation. Spatial interpolation is a typical way of converting discrete gauge observations into areal representation of precipitation, but it requires adequate density of rain gauges. In addition, interpolation methods and associated parameters must be appropriately chosen [47], since errors and uncertainties associated with spatial interpolation are to be propagated to hydrological models.

When gauge stations are too sparse to conduct spatial interpolation, other means could be used to convert pointbased estimates to area-based precipitation estimates. Our blended ST-PRISM method integrates merits of precipitation gauge data and spatial precipitation represented by PRISM. Although it should not be viewed as a replacement for radar data or spatial interpolation applied to rain gauges, it provides an alternative way to capture spatial precipitation, and, in our example, the resulting surface led to model performance as good as that found in the radarcalibrated model. Compared to radar data, ST-PRISM extends the data availably prior to 2002. It is also useful when the density of rain gauges is too low to perform spatial interpolation and eliminates the need to choose and parameterize spatial interpolation methods.

We conducted flood modeling in two watersheds in South Carolina that have experienced severe flooding recently and tested the effects of different precipitation inputs on model performance. Each precipitation source has its own advantages and disadvantages with respect to spatial and temporal coverage and resolution. Our results suggest that there are ways to combine sources to more accurately simulate floods with a simple hydrological model. Specifically, we demonstrate how integrating precipitation gauge data with the widely used PRISM data set extends the temporal availability of an areally representative precipitation data set for flood simulation.

\section{Data Availability}

All data used to support the findings of this study are available from the corresponding author upon request.

\section{Disclosure}

A part of the manuscript was presented in a session at the American Association of Geographers Annual Conference 2018.

\section{Conflicts of Interest}

The authors declare that they have no conflicts of interest.

\section{Acknowledgments}

This research was supported by the Advanced Support for Innovative Research Excellence (ASPIRE) I, Track 2B, from the Office of the Vice President for Research, University of South Carolina, and the National Oceanic and Atmospheric Administration (NOAA) Climate Program Office (Grant no. NA16OAR4310163) to the Carolinas Integrated Sciences and Assessments (CISA).

\section{References}

[1] H. Wu, M. Y. Huang, Q. H. Tang, D. B. Kirschbaum, and P. Ward, "Hydrometeorological hazards: monitoring, forecasting, risk assessment, and socioeconomic responses," Advances in Meteorology, vol. 2016, Article ID 2367939, 3 pages, 2016.

[2] Y. M. Yang, J. Du, L. L. Cheng, and W. Xu, "Applicability of TRMM satellite precipitation in driving hydrological model for identifying flood events: a case study in the Xiangjiang River Basin, China," Natural Hazards, vol. 87, no. 3, pp. 1489-1505, 2017.

[3] A. Juan, Z. Fang, and P. B. Bedient, "Developing a radar-based flood alert system for Sugar Land, Texas," Journal of $\mathrm{Hy}$ drologic Engineering, vol. 22, no. 5, article E5015001, 2017.

[4] M. Azam, H. S. Kim, and S. J. Maeng, "Development of flood alert application in Mushim stream watershed Korea," International Journal of Disaster Risk Reduction, vol. 21, pp. 11-26, 2017.

[5] M. A. Shahid, P. Boccardo, M. Usman, A. Albanese, and M. U. Qamar, "Predicting peak flows in real time through event based hydrologic modeling for a trans-boundary river catchment," Water Resources Management, vol. 31, no. 3, pp. 793-810, 2017.

[6] J. Y. Ye, Y. H. Shao, and Z. J. Li, "Flood forecasting based on TIGGE precipitation ensemble forecast," Advances in Meteorology, vol. 2016, Article ID 9129734, 9 pages, 2016.

[7] P. Arnaud, C. Bouvier, L. Cisneros, and R. Dominguez, "Influence of rainfall spatial variability on flood prediction," Journal of Hydrology, vol. 260, no. 1-4, pp. 216-230, 2002.

[8] I. G. Pechlivanidis, N. McIntyre, and H. S. Wheater, "The significance of spatial variability of rainfall on simulated runoff: an evaluation based on the Upper Lee catchment, UK," Hydrology Research, vol. 48, no. 4, pp. 1118-1130, 2017.

[9] D. J. Seo, J. P. Breidenbach, and E. R. Johnson, "Real-time estimation of mean field bias in radar rainfall data," Journal of Hydrology, vol. 223, no. 3-4, pp. 131-147, 1999. 
[10] W. F. Krajewski and J. A. Smith, "Radar hydrology: rainfall estimation," Advances in Water Resources, vol. 25, no. 8-12, pp. 1387-1394, 2002.

[11] T. J. Ivancic and S. B. Shaw, "Examining why trends in very heavy precipitation should not be mistaken for trends in very high river discharge," Climatic Change, vol. 133, no. 4, pp. 681-693, 2015.

[12] M. Muller, M. Kaspar, A. Valerianova, L. Crhova, E. Holtanova, and B. Gvozdikova, "Novel indices for the comparison of precipitation extremes and floods: an example from the Czech territory," Hydrology and Earth System Sciences, vol. 19, no. 11, pp. 4641-4652, 2015.

[13] T. R. Karl and R. W. Knight, "Secular trends of precipitation amount, frequency, and intensity in the United States," Bulletin of the American Meteorological Society, vol. 79, no. 2, pp. 231-241, 1998.

[14] C. E. D. Todd, J. M. Harbor, and B. Tyner, "Increasing magnitudes and frequencies of extreme precipitation events used for hydraulic analysis in the Midwest," Journal of Soil and Water Conservation, vol. 61, pp. 179-185, 2006.

[15] V. Neary, E. Habib, and M. Fleming, "Hydrologic modeling with NEXRAD precipitation in Middle Tennessee," Journal of Hydrologic Engineering, vol. 9, no. 5, pp. 339-349, 2004.

[16] T. Piman and M. S. Babel, "Prediction of rainfall-runoff in an ungauged basin: case study in the mountainous region of Northern Thailand," Journal of Hydrologic Engineering, vol. 18, no. 2, pp. 285-296, 2013.

[17] National Weather Service Modernization Committee, Future of the National Weather Service Cooperative Observer Network, National Academies Press, Washington, DC, USA, 1998.

[18] G. Salvatore, F. Chiaravalloti, and A. Procopio, "Radar-raingauge rainfall estimation for hydrological applications in small catchments," Advances in Geosciences, vol. 44, pp. 61-66, 2017.

[19] A. Hamedi and H. R. Fuentes, "Comparative effectiveness and reliability of NEXRAD data to predict outlet hydrographs using the GSSHA and HEC-HMS hydrologic models," in Proceedings of the World Environmental and Water Resources Congress 2015: Floods, Droughts, and Ecosystems, pp. 14441453, Austin, TX, USA, May 2015.

[20] J. Koistinen and H. Pohjola, "Estimation of ground-level reflectivity factor in operational weather radar networks using VPR-based correction ensembles," Journal of Applied Meteorology and Climatology, vol. 53, no. 10, pp. 2394-2411, 2014.

[21] C. B. Young, B. M. McEnroe, and R. J. Quinn, "GIS-based processing of NEXRAD rainfall estimates," in Water Resources and the Urban Environment, pp. 165-170, ASCE, Reston, VA, USA, 1998.

[22] H. J. Xie, X. B. Zhou, E. R. Vivoni, J. M. H. Hendrickx, and E. E. Small, "GIS-based NEXRAD Stage III precipitation database: automated approaches for data processing and visualization," Computers \& Geosciences, vol. 31, no. 1, pp. 65-76, 2005.

[23] X. C. Chen, L. P. Zhang, C. J. Gippel, L. J. Shan, S. D. Chen, and W. Yang, "Uncertainty of flood forecasting based on radar rainfall data assimilation," Advances in Meteorology, vol. 2016, Article ID 2710457, 12 pages, 2016.

[24] E. N. Anagnostou, W. F. Krajewski, and J. Smith, "Uncertainty quantification of mean-areal radar-rainfall estimates," Journal of Atmospheric and Oceanic Technology, vol. 16, no. 2, pp. 206-215, 1999.
[25] R. A. Fulton, J. P. Breidenbach, D. J. Seo, D. A. Miller, and T. O'Bannon, "The WSR-88D rainfall algorithm," Weather and Forecasting, vol. 13, no. 2, pp. 377-395, 1998.

[26] S. M. Reed and D. R. Maidment, "Coordinate transformations for using NEXRAD data in GIS-based hydrologic modeling," Journal of Hydrologic Engineering, vol. 4, no. 2, pp. 174-182, 1999.

[27] Y. Lin, "GCIP/EOP Surface: Precipitation NCEP/EMC $4 \mathrm{~km}$ Gridded Data (GRIB) Stage IV Data, Version 1.0," UCAR/ NCAR-Earth Observing Laboratory, Boulder, CO, USA, July 2018, https://doi.org/10.5065/D6PG1QDD.

[28] V. Lopez, F. Napolitano, and F. Russo, "Calibration of a rainfall-runoff model using radar and raingauge data," Advances in Geosciences, vol. 2, pp. 41-46, 2005.

[29] Y. Cho and B. A. Engel, "NEXRAD quantitative precipitation estimations for hydrologic simulation using a hybrid hydrologic model," Journal of Hydrometeorology, vol. 18, no. 1, pp. 25-47, 2017.

[30] W. Charley, A. Pabst, and J. Peters, The Hydrologic Modeling System (HEC-HMS): Design and Development Issues, Hydrological Engineering Center, US Army Corps of Engineers, Washington, DC, USA, 1995.

[31] P. B. Bedient, B. C. Hoblit, D. C. Gladwell, and B. E. Vieux, "NEXRAD radar for flood prediction in Houston," Journal of Hydrologic Engineering, vol. 5, no. 3, pp. 269-277, 2000.

[32] R. Sharma, R. Rudra, S. Ahmed, and B. Gharabaghi, "Comparison of raingauge and NEXRAD radar rainfall data for streamflow simulation for a southern Ontario catchment," Weather Radar and Hydrology, vol. 351, pp. 478-484, 2012.

[33] Federal Emergency Management Agency, 2017, https://www. fema.gov/significant-flood-events.

[34] SC Department of Health and Environmental Control, 2017, http:// www.scdhec.gov/HomeAndEnvironment/DisasterPreparedness/ FloodUpdates/.

[35] Federal Emergency Management Agency News, 2017, https:// www.fema.gov/news-release/2016/12/07/disaster-assistance-tops116-million-hurricane-matthew-survivors-south.

[36] C. Daly, M. Halbleib, J. I. Smith et al., "Physiographically sensitive mapping of climatological temperature and precipitation across the conterminous United States," International Journal of Climatology, vol. 28, no. 15, pp. 2031-2064, 2008.

[37] USDA, "Urban hydrology for small watersheds," Technical Release, vol. 55, pp. 2-6, 1986.

[38] C. Clark, "Storage and the unit hydrograph," Proceedings of the American Society of Civil Engineers, vol. 110, pp. 13331360, 1945.

[39] Iowa Environmental Mesonet, 2017, https://mesonet.agron. iastate.edu/request/asos/hourlyprecip.phtml.

[40] R. D. Harmel and P. K. Smith, "Consideration of measurement uncertainty in the evaluation of goodness-of-fit in hydrologic and water quality modeling," Journal of Hydrology, vol. 337, no. 3-4, pp. 326-336, 2007.

[41] D. N. Moriasi, J. G. Arnold, M. W. Van Liew, R. L. Bingner, R. D. Harmel, and T. L. Veith, "Model evaluation guidelines for systematic quantification of accuracy in watershed simulations," Transactions of the ASABE, vol. 50, no. 3, pp. 885-900, 2007.

[42] K. Price, S. T. Purucker, S. R. Kraemer, J. E. Babendreier, and C. D. Knightes, "Comparison of radar and gauge precipitation data in watershed models across varying spatial and temporal scales," Hydrological Processes, vol. 28, no. 9, pp. 3505-3520, 2014.

[43] J. J. Gourley, Y. Hong, Z. L. Flamig, J. H. Wang, H. Vergara, and E. N. Anagnostou, "Hydrologic evaluation of rainfall 
estimates from radar, satellite, gauge, and combinations on Ft. Cobb Basin, Oklahoma," Journal of Hydrometeorology, vol. 12, no. 5, pp. 973-988, 2011.

[44] E. M. Biggs and P. M. Atkinson, "A comparison of gauge and radar precipitation data for simulating an extreme hydrological event in the Severn Uplands, UK," Hydrological Processes, vol. 25, no. 5, pp. 795-810, 2011.

[45] S. Chintalapudi, H. O. Sharif, S. Yeggina, and A. Elhassan, "Physically based, hydrologic model results based on three precipitation products," Journal of the American Water Resources Association, vol. 48, no. 6, pp. 1191-1203, 2012.

[46] S. Chintalapudi, H. O. Sharif, and H. J. Xie, "Sensitivity of distributed hydrologic simulations to ground and satellite based rainfall products," Water, vol. 6, no. 5, pp. 1221-1245, 2014.

[47] H. J. Xie, X. S. Zhang, B. B. Yu, and H. Sharif, "Performance evaluation of interpolation methods for incorporating rain gauge measurements into NEXRAD precipitation data: a case study in the Upper Guadalupe River Basin," Hydrological Processes, vol. 25, no. 24, pp. 3711-3720, 2011. 

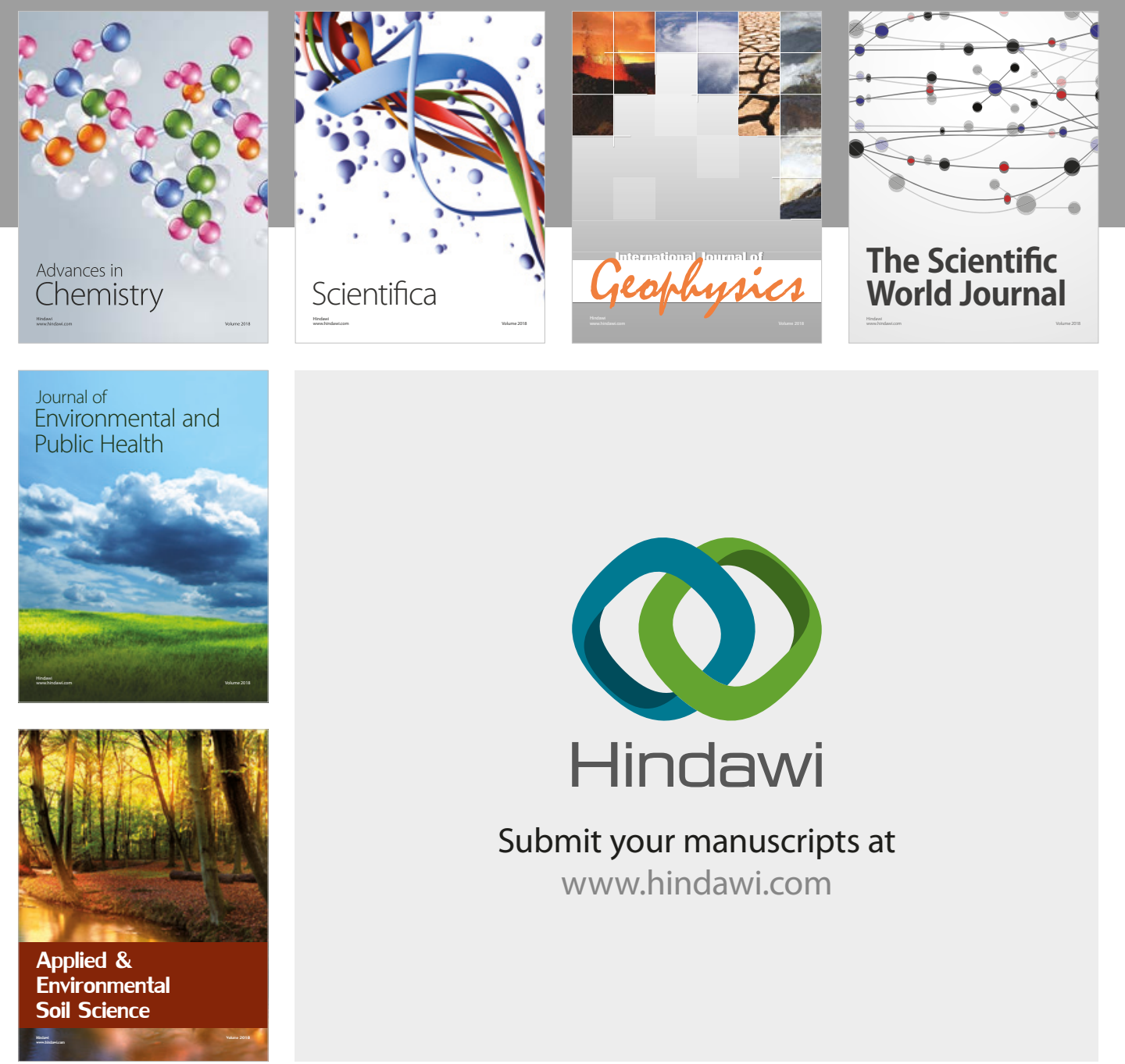

The Scientific

\section{World Journal}
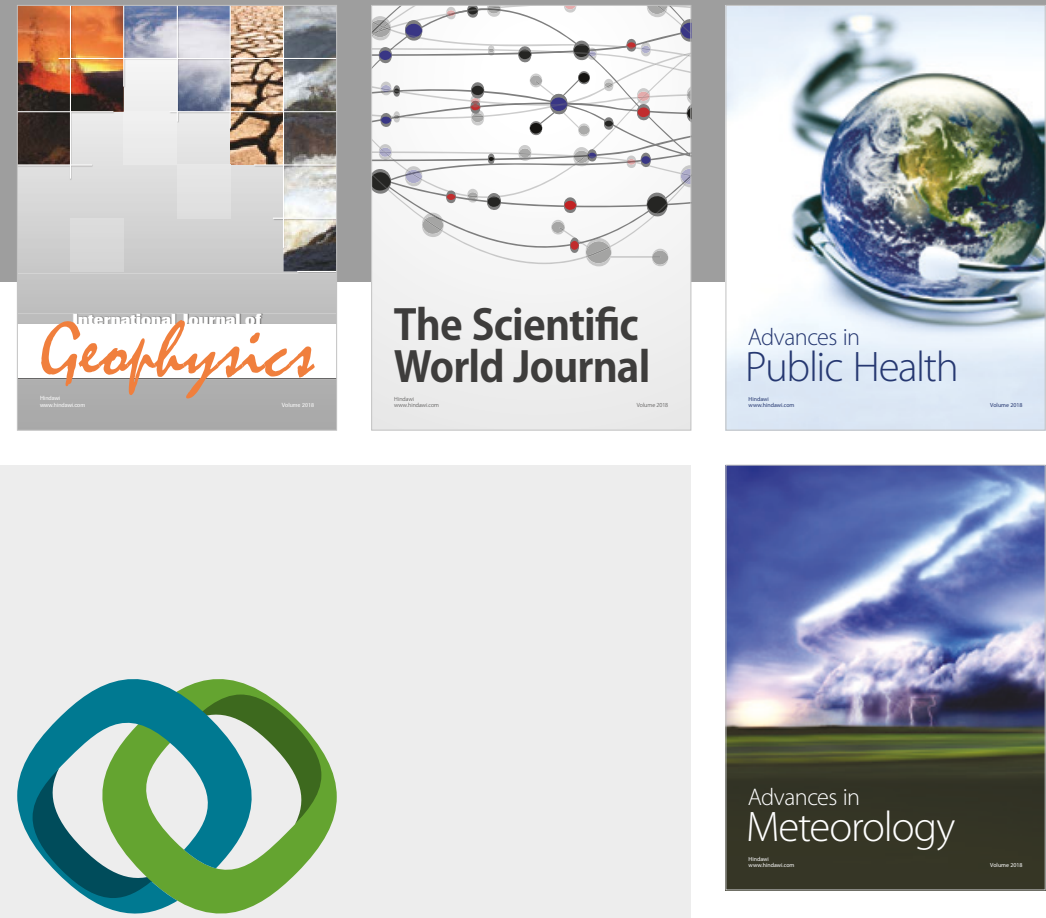

Advan

Public Health

\section{Hindawi}

Submit your manuscripts at

www.hindawi.com
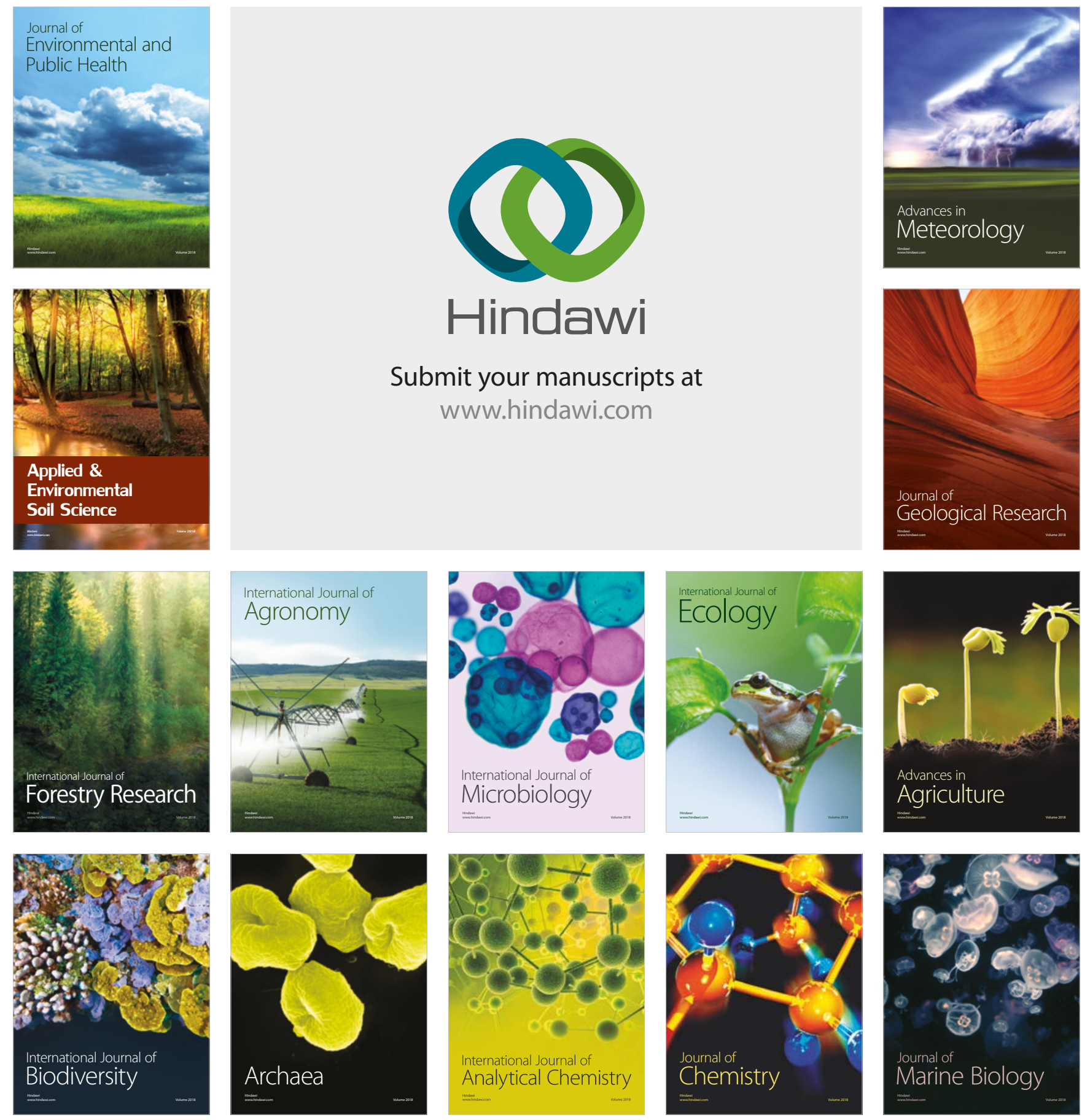